\title{
Cross-disciplinary approaches for measuring parasitic helminth viability and phenotype
}

\author{
EMILY PEAK and KARL F. HOFFMANN
}

Institute of Biological, Environmental and Rural Sciences (IBERS), Aberystwyth University, Aberystwyth, SY23 3DA, UK

Manuscript received on February 23, 2011; accepted for publication on March 16, 2011

\begin{abstract}
Parasitic worms (helminths) within the Phyla Nematoda and Platyhelminthes are responsible for some of the most debilitating and chronic infectious diseases of human and animal populations across the globe. As no subunit vaccine for any parasitic helminth is close to being developed, the frontline strategy for intervention is administration of therapeutic, anthelmintic drugs. Worryingly, and unsurprising due to co-evolutionary mechanisms, many of these worms are developing resistance to the limited compound classes currently being used. This unfortunate reality has led to a renaissance in next generation anthelmintic discovery within both academic and industrial sectors. However, a major bottleneck in this process is the lack of quantitative methods for screening large numbers of small molecules for their effects on the whole organism. Development of methodologies that can objectively and rapidly distinguish helminth viability or phenotype would be an invaluable tool in the anthelmintic discovery pipeline. Towards this end, we describe how several basic techniques currently used to assess single cell eukaryote viability have been successfully applied to parasitic helminths. We additionally demonstrate how some of these methodologies have been adopted for high-throughput use and further modified for assessing worm phenotype. Continued development in this area is aimed at increasing the rate by which novel anthelmintics are identified and subsequently translated into everyday, practical applications.
\end{abstract}

Key words: helminth, schistosome, nematode, viability, phenotype.

\section{INTRODUCTION}

Cell biology, microbiology, immunology and parasitology are four disciplines that involve the study of single cell- or multi-cellular organisms in an attempt to further understand diverse prokaryote and eukaryote biological processes. The outcome or interpretation of these investigations is often dependent upon objective quantification of organism viability. To meet this goal, and in response to the sheer diversity of experimental assays used within these scientific disciplines, many types of complementary or competing technologies have been developed. This variety is most evident in laboratories studying the biology of single cells derived from tissues or

Correspondence to: Karl F. Hoffmann

E-mail: krh@aber.ac.uk unicellular organisms, where flexibility in viability quantitation is necessitated by each cell's unique size, shape or metabolic activity. However, for the parasitologist working with larger, multi-cellular metazoans such as those helminths contained in the phyla Platyhelminthes or Nematoda, the number of viability techniques in use has traditionally been quite limited. As these organisms, exemplified by schistosomes, are incredibly pervasive, it has become quite clear that the need for developing rapid viability assays for identifying novel anthelminths is increasingly important.

Schistosomes are trematode parasites currently affecting more than 200 million people living in tropical and sub-tropical countries of Africa, South America and Asia. Infection with these metazoan worms 
causes a wide range of clinical pathologies (King et al. 2005), which collectively leads to approximately 300,000 deaths per annum (Hotez and Fenwick 2009). Currently, praziquantel is the only effective treatment against the three major species (S. mansoni, S. haematobium and S. japonicum) of schistosome that causes human schistosomiasis. The heavy reliance on this chemotherapy and its inability to protect from reinfection is causing real fears that praziquantel resistant schistosomes may be developing (Doenhoff et al. 2009). With the recent sequencing of this parasite's genome (Berriman et al. 2009, Zhou et al. 2009) providing insight into new gene families and the availability of several functional genomics tools providing the technology useful in characterising them (Brindley and Pearce 2007, Hokke et al. 2007), there is now a strong belief within the schistosome community that novel chemotherapies and immunoprophylactics will be found (Loukas and Bethony 2008). We contend that this objective would be greatly accelerated by the existence and community adoption of reliable high throughput in vitro screening methods to quantify parasite viability and phenotype.

In recent years, this subject has drawn the attention of the schistosome research community (Keiser 2009) and led to a concerted effort to develop new methods for widespread use and adoption. Here, we provide a general overview into the most common methodologies used for measuring eukaryote cell viability and specifically detail those that have shown promise in being adapted for objectively quantifying viability/phenotype of helminth parasites (exemplified by schistosomes and nematodes). It is envisioned that wide adoption of these methodologies within both industrial and academic sectors will enable rapid progress to be made (and confidently replicated) in identifying next generation anthelmintics for veterinary and biomedical use.

\section{METHODS FOR MEASURING SINGLE CELL EUKARYOTE CELL VIABILITY/PHENOTYPE}

The most basic of all techniques for assessing single cell viability or phenotype involves direct bright-field, light microscopic observations of individuals or populations. While this method can provide some information on phenotype, (i.e. motility, shape, and colour) it is not generally applied to all eukaryotic cell types, as many may not display motility or visibly change shape/colour upon death. Therefore, direct microscopy is only rarely used with single cell eukaryotes as an objective measure of viability.

When microscopy alone is unable to differentiate between viable and nonviable cells, many methodologies incorporate a dye or stain to make phenotypic visualisation easier. Indeed, dyes constitute the most common adaptation to microscopic assessment of viability because they are inexpensive, easy to use and provide rapid results. A large selection of dyes/stains are currently in use and can be divided into those that are actively/passively transported across intact cellular membranes ('vital dyes') or those that are preferentially excluded from intact cellular membranes ('non-vital dyes'). Historically, microscopic methodologies that incorporate these dyes/stains have been used to objectively determine whether an individual cell is alive (e.g. by quantifying enzymatic activity on transported dye/stain) or dead (e.g. by measuring the ability of dyes, normally excluded from intact membranes, to cross compromised cell membranes) (Coder 1997). MTT (3-(4,5-Dimethylthiazol-2-yl)-2,5-diphenyltetrazolium bromide) and methylene blue are two such vital dyes that have been successfully used to distinguish eukaryotic cell viability (Levitz and Diamond 1985, Iida et al. 1990). With MTT, the membrane permeable tetrazole is converted into a purple formazoan product inside live cells through the action of the enzyme mitochondrial reductase. The purple formazoan product that is now trapped within the intact cell allows colorimetric distinction between live (purple) and dead (non coloured) cells. Likewise, methylene blue diffuses into both live and dead cells, but in contrast to MTT, is reduced to a colourless form in living cells by the action of enzymes such as catalase (first observed by Cathcart 1906). This feature leads to the discriminatory staining of dead cells (remaining blue). Colorimetric vital dyes of this sort have been successfully adopted within the protozoan parasitology community where, for example, MTT has been used to objectively quantify the viability of Leishmania chagasi promastigotes (Miller et al. 2000). Similarly, the non-fluorescent vital dyes calcein AM and fluorescein diacetate (FDA) are also freely transported across the membranes of intact cells where 
they are enzymatically converted by esterase into fluorescent membrane impermeable products, calcein anion (Decherchi et al. 1997) and fluorescein (Schnurer and Rosswall 1982), respectively. Dead or dying cells with compromised membranes and inefficient esterase activity do not accumulate these fluorescent products and, therefore, cannot be brightly stained (Rotman and Papermaster 1966).

In contrast to membrane permeable vital dyes, another commonly used class of colourimetric or fluorescent compounds is predominantly excluded by intact cellular membranes. These non-vital dyes preferentially stain internal structures of a cell upon breaches in membrane integrity, which occurs following cell death, and are very useful in identifying dead or dying cells. Dyes in this category include the colorimetric dye trypan blue and the fluorescent nucleic acid dyes propidium iodide (PI) and ethidium homodimer (EthD). Upon breaches in cell membrane integrity, trypan blue will preferentially stain intracellular proteins leading to the differential identification of dead cells (blue) in a population (Harper et al. 1981). In parasitological studies, this property has been successfully applied to the protozoan shellfish parasite Bonamia ostreae (Culloty et al. 1999). Here, the authors utilised trypan blue for specifically quantifying differential parasite viability prior to experimentally infecting a diverse group of shellfish species. Similar to trypan blue, the fluorescent DNA dyes PI and EthD will also be excluded from live cells and only cross membranes upon breaches in integrity. In dead cells, PI and EthD can intercalate into double stranded DNA (with little or no sequence preference) (Jones and Senft 1985) as well as RNA and, upon nucleic acid binding, these dyes' fluorescent properties can be enhanced up to 30 fold. These properties have been recently adapted for use in viability screening of Trypanasoma (for example) and, in particular, PI was found to be highly successful in drug development assays or resistance monitoring (Gould et al. 2008).

Due to broad availability and ease of use, both vital and non-vital dyes are popular and widely applied reagents for measuring viability across disciplines. Reagent commercialisation (e.g. Invitrogen's LIVE/DEAD viability/cytotoxicity kit for mammalian cells that utilise both calcein $\mathrm{AM}$ and ethidium homodimer) and aca- demic adaptation (e.g. dual FDA and PI staining of the protozoa parasite Giardia for discriminating viability of these flagellated parasites responsible for giardiasis (Schupp and Erlandsen 1987)) demonstrates the experimental utility of combinatorial dye use. However, a major drawback of measures based solely on vital and non-vital dyes is that they only provide an indirect indication of viability. For example, enzyme activity and breaches in membrane integrity may not always develop uniformly in cells under investigation, thus measurements solely reliant upon dyes/stains could lead to overor under- indications of viability. There is also a limited window in which the selective nature of some of these viability dyes is maintained. For example, it has been observed that trypan blue staining of a tested cell population can non-specifically increase after about 5 mins (Park et al. 2000), which obviously decreases discriminatory power of this dye.

To avoid these issues of indirect measurements of membrane integrity, a variety of competing methods have been developed that can measure cell membrane integrity directly. These tests measure membrane potential (difference in voltage between interior and exterior of cell) by specific quantification of intracellular ion content (Cook and Mitchell 1989). Measurement of intracellular ions as an indication of viability relies on living cells maintaining high intracellular levels of some ions and low intracellular levels of others through active transport mediated by specific channels and pumps across their membranes. When a cell dies, the ability to maintain these ion gradients is lost and this feature can be measured experimentally. One specific way to infer membrane potential of cultured cells involves the measurement of intracellular stores of potassium $\left(\mathrm{K}^{+}\right)$ and sodium $\left(\mathrm{Na}^{+}\right)$ions. Here, Pichugin et al. described a procedure by which all intracellular $\mathrm{K}^{+}$and $\mathrm{Na}^{+}$ stores could be released by trichloroacetic acid (TCA) and measured using a flame photometer (Pichugin et al. 2006). Whilst effective, this test and others like it are not widely used due to the high level of preparative work required (extensive washing of extracellular sources of $\mathrm{K}^{+}$and $\mathrm{Na}^{+}$as well as a $24 \mathrm{hr}$ TCA incubation of target cells to maximise release of intracellular ion stores). Therefore, the use of voltage sensitive dyes such as $\mathrm{DiBAC}_{4}(3)$ (bis-(1, 3-dibutylbarbituric acid)- 
trimethine oxonol) (Yamada et al. 2001) and aminonaphthylethynylpyridinium (ANEP) provide alternative and simpler means to measure membrane potential. DiBAC$_{4}(3)$ is a negatively charged dye that moves into and out of cells in response to membrane potential. For example, $\mathrm{DiBAC}_{4}(3)$ moves into depolarised (positively charged) cells and out of hyperpolarised (negatively charged) cells. Once inside living cells the dye binds to lipids and proteins, causing it to brightly fluoresce (Yamada et al. 2001). Voltage sensitive dyes are mainly used to measure the effects of compounds on membrane potential (Yamada et al. 2001), but they have also been used as a viability measure for protozoan parasites such as Giardia intestinalis and Trichomonas vaginalis (Lloyd et al. 2004).

In addition to quantifying membrane potential, a selection of viability assays have also been developed that directly measure other aspects of cell biology. For example, cellular stores of adenosine-5'-triphosphate (ATP) can be accurately quantified by taking advantage of the bioluminescent properties of recombinant firefly luciferase (Ahmann et al. 1987). The principle of this assay is based on the assumption that greater numbers of viable cells in an assayed sample will produce larger amounts of ATP. Upon lysis of these cells, and in the presence of ATP-utilising luciferase, a corresponding amount of bioluminescene will be observed correlating to the total number of viable cells initially under investigation. Whilst elegant, some challenges in inferring cell viability based on ATP/bioluminescence measures alone may make interpretation of results difficult. For example, incomplete lysis of cells can lead to an underestimation of viability. Also, increases in cellular ATP production (and subsequently measured bioluminescence) can simply be explained by altered metabolic state and not by the absolute amount of viable cells present in a sample. Finally, the destructive nature of this assay precludes further downstream manipulation of the studied cell populations or for the subsequent collection of other phenotypic data, such as shape or granularity. Therefore, in experiments where these issues may be anticipated or encountered, other complementary methods in detecting cell viability may be better suited.

One such method includes electric cell-substrate impedance sensing (ECIS) (Giaever and Keese 1993), which is a label free method for detecting cell viability.
ECIS measures alterations in electrical current passing through gold electrodes placed at the bottom of a culture flask. Changes in current magnitude, caused by cell culturing, are a quantifiable indication of density (cell growth), shape and cell movement. This methodology can provide not only a measurement of viability but also of stress and does not require further manipulation such as lysing of target cells. It has been used for such diverse purposes as measuring cell shape during apoptosis (Arndt et al. 2004) as well as to study the kinetics of cell growth and spreading (Wegener et al. 2000). However, as cells need to be in constant contact with the gold electrodes during culturing, this technique is primarily suited for use with adherent cells.

\section{DEVICES/EQUIPMENT USED FOR COLLECTING SINGLE CELL EUKARYOTE VIABILITY/PHENOTYPE MEASURES}

All cell viability methods that involve the use of stains or fluorescent dyes also require some means of visualising the results and recording the information that is being measured. This might be as basic as a light microscope and a person with a cell counter and a notebook, or it can involve more complicated equipment such as spectrophotometers, microtiter plate readers (equipped to detect fluorescence, bioluminescence, absorbance, etc.), flow cytometers or high content screening systems. Microscopes have the benefit of being readily available, relatively affordable and easy to use; however, they offer only low processivity, which thereby limits throughput. Microscopy can also suffer from subjectivity due to inherent difficulties in agreeing upon a standard set of criteria for use in quantifying cell viability. Because of these limitations, a microscope is most useful in identifying cell viability from small cell populations in a low throughput manner, for example assessing the viability of mouse embryos prior to implantation (Mohr and Trountson 1980). Spectrophotometers and microtiter plate readers automate the collection of data and, importantly, provide an objective measure of viability. Microtiter plate readers are particularly good at processing larger and more complex samples such as those typically found in experiments involving drug screening (Monks et al. 1991, Tian et al. 2007). Flow cytometry is another widespread technique for measuring viability of cell cultures or cell suspensions and has been found to be suitable for use with protozoan parasites such as 
Babesia bovis (Davis et al. 1992) and Plasmodium spp (Totino et al. 2008). It is usually combined with selective dye uptake, either colorimetric, such as trypan blue or fluorescent, such as propidium iodide (Hutter and Eipel 1978). Whilst viability determination measured by a flow cytometer is not as high throughput as what can be achieved with a microtiter plate reader, flow cytometry has higher processivity than microscopy.

High content screening systems such as the ArrayScan VTI from Cellomics and the ImageXpress ULTRA from Molecular Devices are a more sophisticated approach in measuring cell viability. These instruments represent a next generation technology, as they are capable of measuring multiple diverse phenotypic parameters, in addition to viability. High content screening systems generally consist of an epi-fluorescent or a confocal microscope equipped with a camera as well as powerful computer systems capable of high levels of data storage and analysis. These instrument systems may also contain cell culture chambers and robotic handling platforms to facilitate live cell imaging and automated manipulations of cultured cells. Utilising this collection of hardware, high content screening systems can simultaneously collect a multitude of parameters (e.g. cell movement, nuclei morphology and mitochondria transmembrane potential) providing the end user with a rich dataset of information useful in interpreting how a population of cells responds to experimental manipulation (Abraham et al. 2003, $\mathrm{Ng}$ et al. 2010). A recent use of this technology involved high-throughput drug screening of the protozoan parasite Giardia lamblia (Gut et al. 2011). Currently, the initial expense of this equipment combined with the need for specialised software (which may require a great deal of time and expense to develop), are limiting factors in the widespread academic use of these high content screening systems.

\section{WHOLE ORGANISM APPROACHES USED TO QUANTIFY SCHISTOSOMA VIABILITY}

The viability assays detailed above for use with single cell eukaryotes represent only a selection of the scope that is available, with the variety of developed techniques signifying just how important this parameter is to biologists. Parasitologists working with multicellular helminth worms have an equal need for determining if their test subjects are alive and how they are re- sponding to drug tests, RNAi screens and other experimental manipulations. Being multicellular, and hence larger, has provided an advantage in viability screening of these parasites by making microscope investigations relatively straightforward to perform. However, helminth size and microscopic detection of viability are also potential hindrances to the development of high throughput methods, which are often dependent upon assay miniaturisation, objectivity and exacting quantification. Recently, progress has been made in adapting several complementary techniques originally developed for measuring viability in single cell eukaryotes to multicellular parasites and some of these have the potential to be used with schistosomes and other helminth parasites.

From the available selection of viability assays that have been developed for use with single cell eukaryotes (reviewed above), it is surprising to find that only a limited range of techniques have successfully been translated to studies with helminth parasites such as schistosomes. Some difficulties in assay adaptation are likely related to the schistosome's multi-cellular nature, its size $(>1 \mathrm{~cm})$, its tissue complexity and its external tegument bound by a heptalaminate membrane. While this heptalaminate membrane, consisting of two tri-laminate membranes, is thought to be responsible for protecting the parasite from host-mediated immune responses (Skelly and Wilson 2006) it is also selectively permeable to macromolecular molecules, simple compounds and even water (Skelly and Wilson 2006). However, despite these apparent challenges in parasite biology, there is evidence that the problems are potential rather than actual and that some single cell viability techniques can be successfully adapted to schistosomes.

In some ways the size and complexity of schistosomes can be useful attributes for determining viability. Unlike single cells, the size of schistosomes makes morphological differences relatively apparent when visualised by bright-field, light microscopy. The regular movement of both larval and adult schistosomes has also proven to be a valuable trait in assessing schistosome viability in vitro, as lack of movement is a good, though not infallible, indicator of death. Motility, together with other microscopic characteristics (e.g. shape alterations and granularity) (Butterworth et al. 1982) currently comprise the most common indicators for assessing schistosome viability and represent the 'gold 
standard' for assessing drug screening protocols and determining RNAi phenotype within the schistosomiasis research community (Abdulla et al. 2009, Mansour and Bickle 2010, Štefani et al. 2010). However, despite its wide application, bright-field, light microscopic assessment of schistosome viability has several inherent problems. Firstly, this technique requires knowledge of diverse schistosome phenotypes that can only be gained through extensive training. Secondly, using a microscope, detection of schistosome viability will always be subjective due to lack of molecular evidence that death has actually occurred when a schistosome is immobile. Even after proficiency at identifying phenotypes has been attained, this technique is still slow and labour intensive, with a recent study achieving the screening of only 640 potential anti-schistosomula compounds per month (Abdulla et al. 2009). Finally, because of the lack of standardisation between laboratories, replication of results obtained by microscopic means is not always possible.

In an effort to avoid the subjective nature of quantifying schistosome viability from microscopic examination of phenotype alone, further adaptations have been developed and are based on the differentiating potential of some of the colorimetric vital dyes mentioned above. For example, methylene blue has been shown to be a reliable dye for differentially staining dead schistosomula (Gold 1997) and has been used for assessing the viability of mechanically transformed schistosomula (Gold and Flescher 2000). Additionally, Magalhaes et al. (2009) have demonstrated the ability of MTT to assess the viability of adult schistosomes following treatment with curcumin (Magalhaes et al. 2009). Therefore, vital dyes can be successfully translated from single cell viability markers to those studies involving multi-cellular schistosomes.

Fluorescent compounds have also been used to quantify schistosome viability in low-throughput, microscopic-based methods. Compounds tested in this manner include the DNA intercalating dyes ethidium bromide (a dye very similar to ethidium homodimer mentioned above) and PI (Van Der Linden and Deelder 1984, Nyame et al. 2003) as well as carboxyfluorescein (a compound with similar properties to fluorescein diacetate) (Van Der Linden and Deelder 1984). Ethidium bromide has been used as a differential stain of dead schistosomula during microscopy (Van Der Linden and Deelder 1984), whereas PI has successfully been used as a differential stain of dead schistosomula for both microscopy and flow cytometry (Nyame et al. 2003). In contrast to PI and ethidium bromide, carboxyfluorescein has been tested as stain for live schistosomula. However, differentiation proved difficult due to dead schistosomula showing some fluorescence (Van Der Linden and Deelder 1984).

Advancing the use of single dye staining of schistosomula and incorporating ideas pioneered for use with single cell eukaryotes, a dual fluorescent viability assay has recently been developed (Peak et al. 2010). Here the authors combined the use of PI with FDA (Fig. 1) to allow easy assessment of percent schistosomula viability present in a sample. Using a microtiter plate reader, this helminth fluorescent bioassay (HFB) was developed for medium (96-well microtiter plate, 1000 schistosomula/well) or high throughput (384-well format, 200 schistosomula/well) applications. Use of the HFB could allow a 10 -fold increase in the number of compounds screened per month over existing microscope methodologies and has the added advantages of not requiring extensive training in parasite morphology as well as being entirely objective. Currently this assay has been validated with schistosomula and there are indications that it can be adapted for use with adult forms as well as other life stages. Whilst it is clear that the combined use of two fluorescent dyes (PI/FDA) can rapidly and objectively quantify schistosome viability in a high-throughput format, their ability to provide meaningful phenotypic data is somewhat limited. Therefore, other methodologies that allow the automated assessment of phenotype would represent complementary technologies to the HFB.

Imaging software that facilitates non-subjective assessment of schistosome phenotype could be one such method that complements viability readouts. This type of methodology has successfully been employed for use with the miracidial schistosome life stage (Lyddiard et al. 1998). In this study, the authors used electronic imaging techniques to measure the velocity of individual organisms crossing the microscopic field of view as a means of determining the lethality of a dichlorometh- 


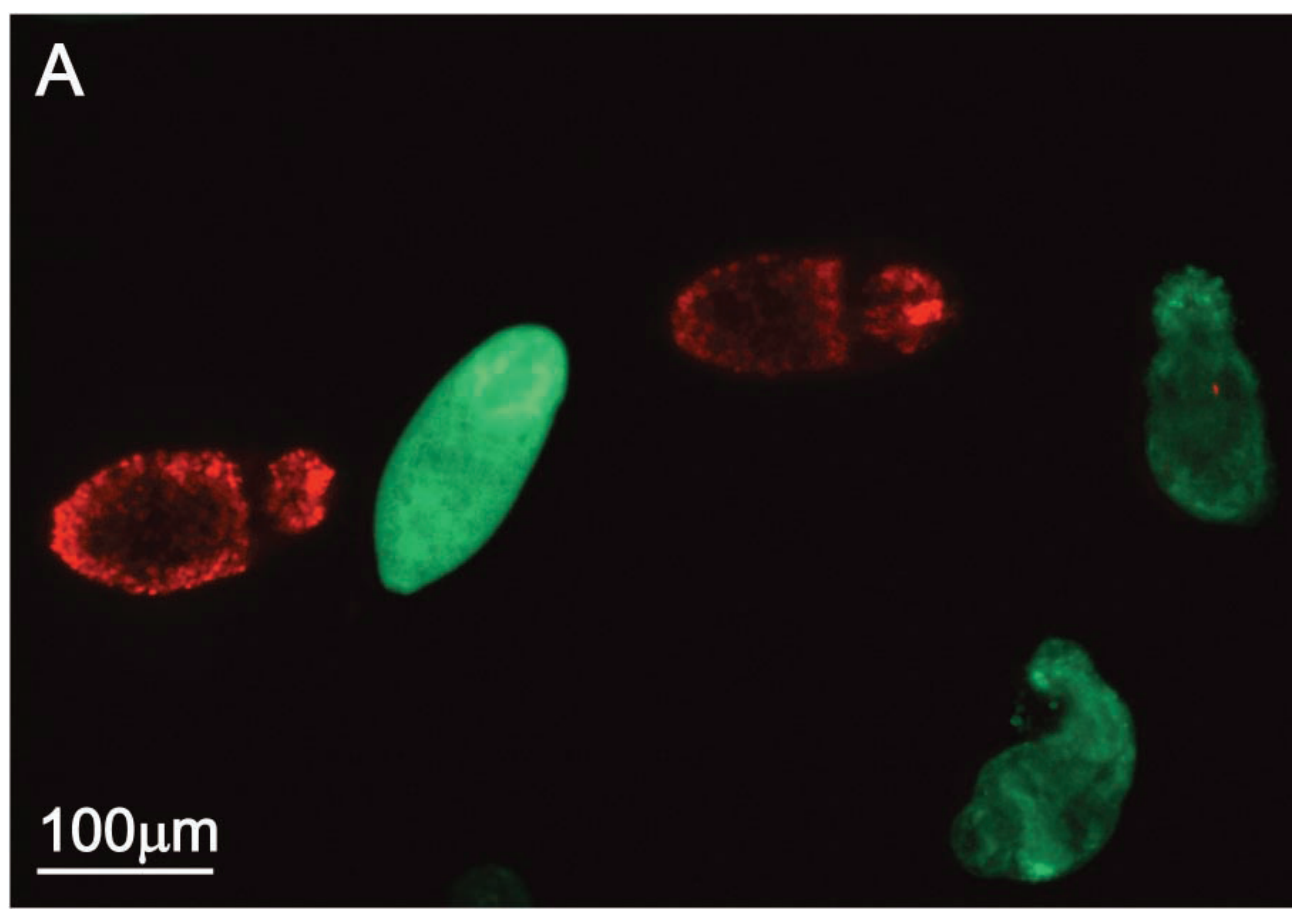

\section{B}
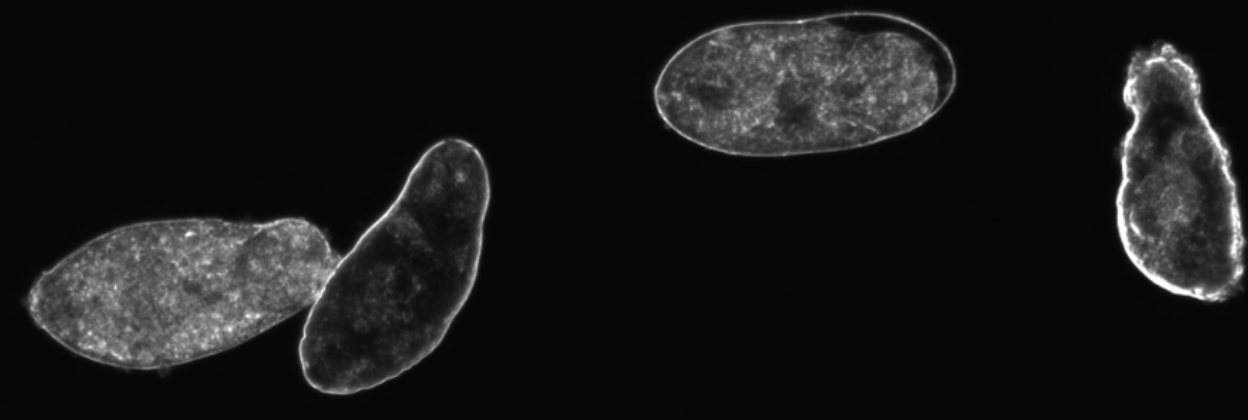

\section{$100 \mu \mathrm{m}$}

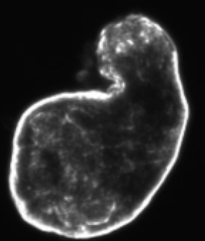

Fig. 1 - Schistosomula viability can be quantified by differential uptake of fluorescein diacetate (FDA) and propidium iodide (PI). Mechanicallytransformed schistosomula were prepared, heat-killed (dead) or left untreated (live) and stained with both FDA and PI fluorophores according to Peak et al. (Peak et al. 2010). Parasite uptake of fluorescent dyes was visualised using an epi-fluorescent microscope equipped with $536 \mathrm{~nm}$ (rhodamine, red) and $494 \mathrm{~nm}$ (FITC, green) filters, while parasite morphology was examined using plane-polarized light. (A) Superimposition of epi-fluorescent spectra collected with both $536 \mathrm{~nm}$ and $494 \mathrm{~nm}$ filters showing dead schistosomula stained red (PI positive, FDA negative) and live schistosomula stained green (FDA positive, PI negative), (B) Differential morphology of dead and live schistosomula detected by plane-polarized light. 
ane extract from the plant Millettia thonningii. However, as miracidia are the only highly motile schistosome life stage, the application of this particular technique to other life cycle forms would likely be limited (perhaps useful for cercariae (Haeberlein and Haas 2008)). The development of high content screening systems, as previously discussed, is an important step on the road to developing real time visualisation data for all schistosome lifecycle stages. However, while there have been calls for its development (Mansour and Bickle 2010), there is no published evidence that this has been achieved to date.

One technological advance that may offer a solution to the challenge of quantifying helminth phenotype, until high content screening is an affordable reality, is a motility assay recently developed by Smout et al. (Smout et al. 2010). This assay, which uses the xCELLigence system from Roche, is similar to the ECIS methodology developed by Giaever and Keese and is based on the detection of changing electrical currents running through mini gold electrodes incorporated into the bottom of tissue culture plates (Giaever and Keese 1993). As schistosomes and indeed most helminths (including immature and mature stages) are quite dense, they will sediment during in vitro culturing and make contact with the gold electrodes. Changes to the culturing conditions that impact a worm's physiology will likely alter its behaviour or phenotype and thus cause a measurable fluctuation in current across the electrodes. As the action of many anthelmintics is reflected by their ability to affect the motility of the target parasite (Bennett and Pax 1986), the magnitude of these measurable current fluctuations may be an indicator of compounds that have potential therapeutic activity. Smout et al demonstrated that they could use this biophysical characteristic to assess anthelmintic activity of compounds in real time in a high throughput fashion (Smout et al. 2010). This technology was applied to adult schistosomes (as well as several species of parasitic nematodes - see below) and used to illustrate that increasing doses of praziquantel cause decreased signal from adult schistosomes, allowing a dose dependent curve to be generated. Whether this technology can be applied to larval schistosome life stages is currently unknown, but appears feasible. This motility assay may provide a superior methodology to microscopy for removing subjectivity in characterising helminth phenotype as well as to make available a technology that could allow direct comparisons of results from different laboratories. The initial cost of the xCELLigence equipment and its limitation of only being useful for experiments involving helminth lifecycle stages that can be cultured in contact with the electrode may restrict its widespread use.

While the above viability/phenotypic assays all involve the use of whole schistosomes, alternative highthroughput molecular approaches in drug discovery are being developed that are complementary to the above technologies. These approaches aim to reduce the need for screening whole living organisms and instead focus on specifically measuring the activity of helminth molecular targets involved in key metabolic or enzymatic pathways (Caffrey 2007). The ability to study a compound's effect on individual target molecules outside of the whole organism removes potential confounding factors, such as tegumental penetration and detoxification via schistosome metabolism. Furthermore, target based approaches in drug discovery also allow for a greater understanding into the mechanisms of drug action, thus providing opportunities for optimisation of activity. Once drug targets and appropriate compounds that affect target activity have been identified, there will be possibilities for chemists to resolve issues of penetration and metabolism separately during iterative whole organism screening (Woods and Knauer 2010). The recent publication of both S. mansoni and S. japonicum genomes (Berriman et al. 2009, Zhou et al. 2009) has provided a multitude of data readily accessible to this target based approach. Whilst this methodology can greatly reduce the number of whole organisms being used in drug discovery, it will not eliminate them entirely. Once a compound demonstrates efficacy during target based high-throughput screening, it must be tested on whole organisms (using an assay as described above) as well as in an experimental model of schistosomiasis to ensure that anthelmintic efficacy is maintained at no detriment to the host's survival. A recent success in this area involved the discovery of oxadiazoles as novel anti-schistosomal compounds that effectively disrupt the thioredoxin glutathione reductase (TGR) antioxidant pathway (Kuntz et al. 2007, Sayed et al. 2008, 
Simeonov et al. 2008, Rai et al. 2009). Here, using both chemical inhibition (auranofin) and molecular (RNAi) methods, the authors identified TGR as a key schistosome enzyme in the antioxidant pathway (Kuntz et al. 2007). By developing a high-throughput assay using recombinantly expressed TGR in a microtiter plate format, the authors subsequently identified oxadiazoles as a potential new drug class for treating schistosomiasis (Sayed et al. 2008). The anti-schistosomal activity of oxadiazoles was subsequently confirmed in a whole organism bioassay using both juvenile and adult worms (based on microscopic observations of worm phenotype) as well as during experimental schistosomiasis in a murine model (Sayed et al. 2008). Whilst this target based approach clearly can identify novel anthelmintics, whole organism bioassays need to be integrated in this pipeline of drug discovery to ensure that the effect observed on a target is not lost on a whole organism. This is a real concern (Woods and Knauer 2010) and is one of the major drivers for development of high-throughput whole organism bioassays such as the helminth fluorescent bioassay (Peak et al. 2010). We contend that target based high-throughput screening approaches are not suitable for use as standalone technology in the search for novel anthelmintics, but they can effectively complement the whole organism based approach and may be utilised upstream in the drug discovery pipeline when the biology of the target is known.

\section{METHODOLOGIES FOR CHARACTERISING NEMATODE VIABILITY AND PHENOTYPE}

Trematodes such as schistosomes are not the only multicellular organisms for which viability and phenotypic state needs to be assessed in the context of disease control. Pathogenic nematodes also present a significant health and welfare problem for both humans and livestock. Currently more than 1 billion people worldwide are infected with at least one species of soil transmitted nematode (Bethony et al. 2006) and the health and general productivity of livestock, particularly small ruminants in the tropics, is severely impaired by gastrointestinal nematode infection (Marie-Magdeleine et al. 2010). Repeated use of anthelmintic drugs represents the most common control strategy for these parasites and the emergence of drug resistance is a very real threat (Wolstenholme et al. 2004). Significant resistance has already been reported for benzimidazoles, including thiabendazole, in Haemonchus contortus and ivermectin and moxidectin in cyathostomes (Silvestre et al. 2002, Owen et al. 2008). As the global animal anthelmintics market was valued at 3.7 billion USD in 2002 (Smout et al. 2010), many pharmaceutical companies (e.g. Pfizer, Merck, Novartis and Bayer (Woods and Knauer 2010)) are constantly searching for new drug classes in an effort to meet market needs. A trend within these companies is to revisit whole organism phenotyping as a method to screen vast libraries of proprietary compounds for lead identification (Woods and Knauer 2010). As can be imagined, a robust and quantifiable assay for nematode phenotyping would benefit the search for novel anthelmintics. However, similar to Schistosoma, the current gold standard for assessing the responses of parasitic nematodes to drug treatment is through microscopic determination of phenotype (Smout et al. 2010). Parameters including shape (e.g. coiled or flaccid) and motility (e.g. paralysed or sluggish) are the most easily discernable. Therefore, the development of a highthroughput method for screening nematode viability or phenotype would greatly benefit both the pharmaceutical and research communities.

Unlike work performed on both single cell eukaryotes and schistosomes, there is a paucity of examples for the use of vital and non-vital dyes in whole organism, high throughput screening of nematode viability. Examples are limited to MTT staining of filarial nematodes including Onchocerca volvulus (Comley et al. 1989) and SYTOX green (DNA intercalating stain with fluorescent properties similar to EthD and PI) staining of the non-parasitic nematode Caenorhabditis elegans (Gill et al. 2003). The lack of studies reporting the use of dyes/stains in distinguishing nematode viability is likely due to the robust nature of the nematode's cuticle, which prevents many dyes/stains from entering the coelomate body plan as well as the fact that phenotype such as motility, as opposed to viability, is the most commonly accepted readout utilised in both academia and industry (Bennett and Pax 1986, Smout et al. 2010). Therefore, the focus of the nematode community seems to be on developing more sensitive and objectively quantifiable ways to identify differential changes in parasite motility upon experimental treatment. 
TABLE I

Complementary methods for assessing helminth viability and identifying novel anthelmintics.

\begin{tabular}{l|c|c|l}
\hline \multicolumn{1}{c|}{ Method } & Schistosomes & Nematodes & \multicolumn{1}{|c}{ References $^{\text {a }}$} \\
\hline Non-vital dyes & & & \\
Methylene blue & Yes & No & Gold 1997 \\
Propidium iodide & Yes & No & Nyame et al. 2003, Peak et al. 2010 \\
Ethidium bromide & Yes & No & Van Der Linden and Deelder 1984 \\
Sytox Green & No & Yes & Gill et al. 2003 \\
\hline Vital dyes & & & \\
MTT & Yes & Yes & Comley et al. 1989, Magalhães et al. 2009 \\
Carboxyfluorescien & Yes & No & Van Der Linden and Deelder 1984 \\
Fluorescein diacetate & Yes & No & Peak et al. 2010 \\
\hline Direct measurements & & & \\
xCELLigence & Yes & Yes & Smout et al. 2010 \\
Motility meter & No & Yes & Bennett and Pax 1986 \\
Video imaging & Yes & No & Lyddiard et al. 1998 \\
\hline Target based & & & \\
Recombinant molecules & Yes & Yes & Sayed et al. 2008, Gloeckner et al. 2010 \\
\hline
\end{tabular}

${ }^{a}$ indicates studies where methods has been successfully used in either trematode or nematode investigations.

One methodology developed specifically for the analysis of nematode motility is based upon the physical properties of light disruption where a photodiode measures a beam of light transmitted through a vertical column of culture medium (Bennett and Pax 1986). Using this methodology, the authors demonstrated that live, motile nematodes within the culture media caused intermittent disruptions in a light beam shone through the culture vessel, while dead or immobile nematodes caused no disruption, or continuous disruption. The authors additionally found a direct correlation between lower frequency disruptions and lower motility in the nematodes being assayed, thus providing a quantitative metric. This test was originally developed using Nippostrongylus brasiliensis, Ascaris suum, Brugia pahangi and Caenorhabditis elegans (Bennett and Pax 1986) but was later demonstrated as effective for use with Haemonchus contortus (Folz et al. 1987). Despite the fact that this test seems to present a rapid and simple means of determining nematode viability, there is little evidence that its use has become widespread, possibly due to the non-commercial source of the equipment being used.

Another more recent technique to provide a means of quantifying nematode motility utilises the previously- described assay developed by Smout et al. where fluctuations in electrical currents are measured by the xCELLigence system (Smout et al. 2010). The authors demonstrated differential motility differences between ivermectin treated larval Strongyloides ratti and Haemonchus contortus compared to control worms as well as thiabendazole treated adult Ancylostoma caninum compared to controls. As the xCELLigence system also works on adult schistosomes (see above), this single approach in measuring worm motility has broad applications for multiple parasitic helminth species (within the Platyhelminthes and Nematoda) and represents a promising methodology for academic and industrial consideration.

\section{CONCLUSIONS}

Throughout the last century, a diverse array of viability assays has been developed for use with single cells derived from tissues or unicellular organisms. The fundamental principles underlying progress in this area have been invaluable for the improvement of viability screening techniques for use with multi-cellular helminth parasites (Table I). It is clear from recent publications that low throughput, subjective measures of 
helminth viability, motility and phenotype are now beginning to be superseded by emerging quantitative technologies within laboratories studying the biology of both nematodes and trematodes (Sayed et al. 2008, Peak et al. 2010, Smout et al. 2010). It is anticipated that further quantitative advancements in this area will continue to evolve and positively impact upon basic investigations of helminth biology. More importantly, utilisation of these high-throughput tools offers a tremendous opportunity for the rapid discovery of urgently needed drug classes useful in the control of these devastating parasitic infections.

\section{ACKNOWLEDGMENTS}

We thank Dr. Iain Chalmers for helpful comments and Dr. Rhian Hayward for critically reviewing this manuscript.

\section{RESUMO}

Vermes parasíticos (helmintos) dos filos Nematoda e Platelmintos são responsáveis por algumas das doenças infecciosas crônicas e mais debilitantes das populações humana e animal em todo o globo. Já que nenhuma vacina está prestes a ser desenvolvida para nenhum parasita helmíntico, a frente estratégica de intervenção é a administração de drogas terapêuticas anti-helmínticas. De maneira preocupante, e não surpreendente devido a mecanismos coevolutivos, muitos destes vermes estão desenvolvendo resistência às limitadas classes de compostos que têm sido usados no momento. Esta infeliz realidade levou a um renascimento na descoberta de uma nova geração de anti-helmínticos tanto no setor acadêmico quanto no industrial. Contudo, um importante gargalo neste processo é a falta de métodos quantitativos para testar um grande número de pequenas moléculas em relação aos efeitos sobre o organismo inteiro. $\mathrm{O}$ desenvolvimento de metodologias que possam distinguir objetiva e rapidamente a viabilidade dos helmintos ou o fenótipo seria uma ferramenta valiosa para canalizar a descoberta de anti-helmínticos. Para este fim, descrevemos aqui como muitas técnicas básicas, correntemente usadas para avaliar a viabilidade de células únicas de eucariotos, têm sido aplicadas com sucesso para helmintos parasíticos. Adicionalmente demonstramos como algumas destas metodologias foram adotadas para uso em larga escala e além disso modificadas para avaliar o fenótipo de vermes. O desenvolvimento contínuo nesta área está voltado para aumentar a taxa com que novos anti-helmínticos são identificados e subsequentemente traduzidos em aplicações práticas cotidianas.

Palavras-chave: helminto, esquistossoma, nematodo, viabilidade, fenótipo.

\section{REFERENCES}

Abdulla MH, Ruelas DS, Wolff B, Snedecor J, Lim KC, Xu F, Renslo AR, Williams J, McKerROW JH AND CAFFREY CR. 2009. Drug Discovery for Schistosomiasis: Hit and Lead Compounds Identified in a Library of Known Drugs by Medium-Throughput Phenotypic Screening. PLoS Negl Trop Dis 3: e478.

ABraham VC, TAYlor DL AND Haskins JR. 2003. High content screening applied to large-scale cell biology. Trends Biotechnol 22: 15-22.

Ahmann FR, Garewal HS, Schifman R, Celniker A AND RODNEY S. 1987. Intracellular adenosine triphosphate as a measure of human tumor cell viability and drug modulated growth. In Vitro Cell Dev Biol Plant 23: 474-480.

Arndt S, Seebach J, Psathanki K, Galla H-J And Wegener J. 2004. Bioelectrical impedance assay to monitor changes in cell shape during apoptosis. Biosens Bioelectron 19: 583-594.

Bennett JL And Pax RA. 1986. Micromotility meter: an instrument designed to evaluate the action of drugs on motility of larval and adult nematodes. Parasitology 93: $341-346$

Berriman M, HaAs BJ, LoVerde PT, Wilson RA, Dillon GP, Cerqueira GC, Mashiyama St, AlLAZIKANi B, ANDRAde LF AND AShTON PD. 2009. The genome of the blood fluke Schistosoma mansoni. Nature 460: 352-358.

Bethony J, Brooker S, Albonico M, Geiger SM, Loukas A, Diemert D ANd Hotez PJ. 2006. Soiltransmitted helminth infections: ascariasis, trichuriasis, and hookworm. Lancet 367: 1521-1532.

Brindley PJ AND PeArCe EJ. 2007. Genetic manipulation of schistosomes. Int J for Parasitol 37: 465-473.

Butterworth ae, Taylor DW, Veith mC, Vadas MA, Dessein A, STURrock RF AND Wells E. 1982. Studies on the mechanisms of immunity in human schistosomiasis. Immunol Rev 61: 5-39.

CAFFREY CR. 2007. Chemotherapy of schistosomiasis: present and future. Curr Opin Chem Biol 11: 433-439.

CATHCART MD. 1906. Upon the reduction of methylene blue by cow's milk. J Hyg 6: 300-303. 
CODER D. 1997. Assessment of cell viability. In: CURRENT Protocols in Cytometry. J Wiley \& Sons, Inc, p. 9.2.1-9.2.14.

Comley JC, ReEs MJ, Turner CH And Jenkins DC. 1989. Colorimetric quantitation of filarial viability. Int $J$ Parasitol 19: 77-83.

CoOK JA AND Mitchell JB. 1989. Viability measurements in mammalian cell systems. Anal Biochem 179: 1-7.

Culloty SC, Novoa B, Pernas M, Longshaw M, Mulcahy MF, Feist SW ANd Figueras A. 1999. Susceptibility of a number of bivalve species to the protozoan parasite Bonamia ostreae and their ability to act as vectors for this parasite. Dis Aquat Org 37: 73-80.

Davis WC, Wyatt CR, Hamilton MJ ANd Goff WL. 1992. A rapid reliable method of evaluating growth and viability of intraerythrocytic protozoan hemoparasites using fluorescence flow cytometry. Mem Inst Oswaldo Cruz, Rio de Janeiro 87: 235-239.

Decherchi P, Cochard P ANd Gauthier P. 1997. Dual staining assessment of Schwann cell viability within whole peripheral nerves using calcein-AM and ethidium homodimer. J Neurosci Methods 71: 205-213.

Doenhoff MJ, Hagan P, Cioli D, Southgate V, Pica-Mattoccia L, Botros S, Coles G, Tchuem TChuenté LA, Mbaye A And Engels D. 2009. Praziquantel: its use in control of schistosomiasis in subSaharan Africa and current research needs. Parasitology 136: 1825-1835.

Folz SD, Pax RA, Thomas EM, Bennett JL, LeE BL AND CONDER GA. 1987. Detecting in vitro anthelmintic effects with a micromotility meter. Vet Parasitol 24: 241-250.

Giaever I AND KeEse CR. 1993. A morphological biosensor for mammalian cells. Nature 366: 591-592.

Gill MS, Olsen A, SAMPAyo JN ANd Lithgow GJ. 2003. An automated high-throughput assay for survival of the nematode Caenorhabditis elegans. Free Radic Biol Med 35: 558-565.

Gloeckner C, Garner AL, Mersha F, Oksov Y, Tricoche N, Eubanks LM, Lustigman S, KaufmanN GF AND JANDA KD. 2010. Repositioning of an existing drug for the neglected tropical disease Onchocerciasis. Proc Natl Acad Sci USA 107: 3424.

GolD D. 1997. Assessment of the viability of Schistosoma mansoni schistosomula by comparative uptake of various vital dyes. Parasitol Res 83: 163-169.
GOLD D AND FLESCHER E. 2000. Influence of mechanical tail-detachment techniques of schistosome cercariae on the production, viability, and infectivity of resultant schistosomula: a comparative study. Parasitol Res 86: $570-572$.

Gould MK, Vu XL, SeEbeck T ANd De Koning HP. 2008. Propidium iodide-based methods for monitoring drug action in the kinetoplastidae: comparison with the Alamar Blue assay. Anal Biochem 382: 87-93.

Gut J, Ang KKH, Legac J, ARKIn MR, Rosenthal PJ AND MCKERROW JH. 2011. An image-based assay for high throughput screening of Giardia lamblia. J Microbiol Meth 84: 398-405.

Haeberlein S AND HaAs W. 2008. Chemical attractants of human skin for swimming Schistosoma mansoni cercariae. Parasitol Res 102: 657-662.

Harper BL, Fine DP, Guckian JC and Cavallo T. 1981. Trypan blue inhibition of complement receptor funtion on various cells. Immunology 62: 61-66.

Hokke CH, Fitzpatrick JM AND HofFmann KF. 2007. Integrating transcriptome, proteome and glycome analyses of Schistosoma biology. Trends Parasitol 23: 165-174.

Hotez PJ AND Fenwick A. 2009. Schistosomiasis in Africa: an emerging tragedy in our new global health decade. PLoS Negl Trop Dis 3: e485-e489.

HutTer KJ AND Eipel HE. 1978. Advances in Determination of Cell Viability. J Gen Microbiol 107: 165167.

IIDA H, Yagawa Y AND ANRAKU Y. 1990. Essential role for induced $\mathrm{Ca} 2^{+}$influx followed by $\left[\mathrm{Ca} 2^{+}\right]$rise in maintaining viability of yeast cells late in the mating pheromone response pathway. J Biol Chem 265: 1339113399.

JONES K AND SENFT J. 1985. An improved method to determine cell viability by simultaneous staining with fluorescein diacetate-propidium iodide. J Histochem Cytochem 33: 77-79.

KEISER J. 2009. In vitro and in vivo trematode models for chemotherapeutic studies. Parasitology 137: 589-603.

KING CH, DickMAN K AND TISCH DJ. 2005. Reassessment of the cost of chronic helmintic infection: a metaanalysis of disability-related outcomes in endemic schistosomiasis. Lancet 365: 1561-1569.

Kuntz AN, Davioud-Charvet E, Sayed AA, Califf LL, Dessolin J, Arnér ES and Williams DL. 2007. Thioredoxin Glutathione Reductase from Schisto- 
soma mansoni: An Essential Parasite Enzyme and a Key Drug Target. PLoS Medicine 4: e206.

LEVITZ SM AND DIAMOND RD. 1985. A rapid colorimetric assay of fungal viability with the tetrazolium salt MTT. J Infect Dis 152: 938-945.

Lloyd D, Harris JC, Biagini GA, Hughes MR, MaROULIS S, BERNARD C, WADLEY RB AND EDWARDS MR. 2004. The plasma membrane of micoraerophilic protists: oxidative and nitrosative stress. Microbiology 150: 1183-1190.

Loukas A And Bethony JM. 2008. New drugs for an ancient parasite. Nature Med 14: 365-367.

LydDiARd JRA, BARTLETT A, GRAY B AND WhitFIELD PJ. 1998. The use of video-imaging to assesss the sublethal impact of plant secondary compounds on Schistosoma mansoni miracidia. J Helminthol 72: 237-241.

Magalhaes LG, Machado CB, Morais ER, Bueno de Carvalho Moreira E, Soares CS, da Silva SH, DA Silva Filho AA ANd Rodrigues V. 2009. In vitro schistosomicidal activity of curcumin against Schistosoma mansoni adult worms. Parasitol Res 104: 11971201.

MANSOUR NR AND BICKLE QD. 2010. Comparison of microscopy and Alamar blue reduction in a larval based assay for schistosome drug screening. PLoS Negl Trop Dis 4: e795.

Marie-Magdeleine C, Udino L, Philibert L, Bocage B AND ARCHIMEDE H. 2010. In vitro effects of cassava (Manihot esculenta) leaf extracts on four developmental stages of Haemonchus controtus. Vet Parasitol 173: 8592.

Miller MA, McGowan SE, Gantt KR, Champion M, Novick SL, ANDERSEn KA, BACCHI CJ, YARLETT N, BRitigan BE AND Wilson ME. 2000. Inducible resistance to oxidant stress in the protozoan Leishmania chagasi. J Biol Chem 275: 33883-33889.

Mohr LR AND Trountson AO. 1980. The use of fluorescein diacetate to assess embyro viability in the mouse. J Reprod Fertil 58: 189-196.

MONKS A ET AL. 1991. Feasibility of a high-flux anticancer drug screen using a diverse panel of cultured human tumor cell lines. J Natl Cancer Inst 83: 757-766.

Ng AYJ, Rajapakse JC, Welsch Re, Matsudaira PT, Horodincu V and Evans JG. 2010. A Cell Profiling Framework for Modeling Drug Responses from HCS Imaging. J Biomol Screen 15: 858.
Nyame AK, Lewis FA, Doughty BL, CORREA-OliveIRA R AND CUMmingS RD. 2003. Immunity to schistosomiasis: glycans are potential antigenic targets for immune intervention. Exp Parasitol 104: 1-13.

Owen J, Slocombe D, Cote JF And de Gannes RVG. 2008. The persistence of benzimidazole-resistant cyathostomes on horse farms in Ontario over 10 years and the effectiveness of ivermectin and moxidectin against these resistant strains. Can Vet J 49: 56-60.

PARK J-C, HWANG Y-S AND SUH H. 2000. Viability evaluation of engineered tissues. Yonsei Med J 41: 836-844.

Peak E, Chalmers IW and Hoffmann KF. 2010. Development and Validation of a Quantitative, High-Throughput, Fluorescent-Based Bioassay to Detect Schistosoma Viability. PLoS Negl Trop Dis 4: e759.

Pichugin Y, FAHY GM AND MoRIN R. 2006. Cryopreservation of rat hippocampal slices by vitrification. Cryobiology 52: 228-240.

RAI G ET AL. 2009. Structure mechanism insights and the role of nitric oxide donation guide the development of oxadiazole-2-oxides as therapeutic agents against schistosomiasis. J Med Chem 52: 6474-6483.

Rotman B And PApermaster BW. 1966. Membrane Properties of Living Mammalian Cells as Studied by Enzymatic Hydrolysis of Fluorogenic Esters. Proc Natl Acad Sci USA 55: 134-141.

Sayed AA, Simeonov A, Thomas CJ, Inglese J, Austin CP AND WILliams DL. 2008. Identification of oxadiazoles as new drug leads for the control of schistosomiasis. Nature Med 14: 407-412.

SCHNURER J AND Rosswall T. 1982. Fluorescein diacetate hydrolysis as a measure of total microbial activity in soil and litter. Appl Environ Microbiol 43: 1256-1261.

SCHUPP DG AND ERLANDSEN SL. 1987. A new method to determine Giardia Cyst viability: correlation of fluorescein diacetate and propidium iodide staining with animal infectivity. Appl Environ Microbiol 53: 704-707.

Silvestre A, Leignel V, Berrag B, Gasnier N, HumBert J-F, Chartier C And Cabaret J. 2002. Sheep and goat nematode resistance to anthelmintics: pro and cons among breeding management factors. Vet Res 33.

Simeonov A, Jadhav A, SAyed AA, WAng Y, NelSON ME, Thomas CJ, Inglese J, Williams DL AND AUstin CP. 2008. Quantitative High-Throughput Screen Identifies Inhibitors of the Schistosoma mansoni Redox Cascade. PLoS Negl Trop Dis 2. 
SKelly PJ AND WiLson RA. 2006. Making sense of the schistosome surface. Adv Parasitol 63: 185-284.

Smout MJ, Kotze AC, McCARThy JS AND LouKas A. 2010. A novel high throughput assay for anthelmintic drug screening and resistance diagnosis by real-time monitoring of parasite motility. PLoS Negl Trop Dis 4: e885.

Štefani S, DVořák J, Horn M, Braschi S, SoJKa D, Ruelas D, Suzuki B, Lim KC, Hopkins SD AND MCKERROW JH. 2010. RNA Interference in Schistosoma mansoni Schistosomula: Selectivity, Sensitivity and Operation for Larger-Scale Screening. PLoS Negl Trop Dis 4: e850.

Tian H, Ip L, Luo H, Chang DC and Luo KQ. 2007. A high throughput drug screen based on fluorescence resonance energy transfer (FRET) for anticancer activity of compounds from herbal medicine. Br J Pharmacol 150: 321-334.

TOTINO PRR, DANIEL-RIBEIRO CT, CORTE-REAL S AND DE FATIMA FerreirA-DA-CrUz M. 2008. Plasmodium falciparum: erythrocytic stages die by autophagic-like cell death under drug pressure. Exp Parasitol 118: 478-486.

VAN Der Linden PWG AND DeElder AM. 1984. Schistosoma mansoni: A Diamidinophenylindole Probe for in Vitro Death of Schistosomula. Exp Parasitol 57: 125-131.
Wegener J, Keese CR And Giaever I. 2000. Electric cell-substrate impedance sensing (ECIS) as a noninvasive means to monitor the kinetics of cell spreading to artificial surfaces. Exp Cell Res 259: 158-166.

Wolstenholme AJ, Fairweather I, Prichard R, von SAMSON-Himmelstjerna G AND SANGSter NC. 2004. Drug resistance in veterinary helminths. Trends Parasitol 20: 469-476.

Woods DJ AND KNAUER CS. 2010. Discovery of veterinary antiparasitic agents in the $21^{\text {st }}$ century: a view from industry. Int J Parasitol 40: 1177-1181.

Yamada A, Gaja N, Ohya S, Katsuhiko M, Narita H, OHWADA T AND IMAIZUMI Y. 2001. Usefulness and limitation of $\mathrm{DiBAC}_{4}(3)$, a voltage-sensitive fluorescent dye, for the measurement of membrane potentials regulated by recombinant large conductance $\mathrm{Ca} 2{ }^{+}$-activated $\mathrm{K}^{+}$channels in HEK293 cells. Jpn. J Pharmacol 86: $342-350$.

Zhou Y, Zheng H, Chen Y, Zhang L, WANG K, GUO J, HuAng Z, Zhang B, HuANG W AND Jin K. 2009. The Schistosoma japonicum genome reveals features of host-parasite interplay. Nature 460: 345-351. 